\title{
A CLINICAL AND HAEMODYNAMIC STUDY OF VENTRICULAR SEPTAL DEFECT IN INFANTS
}

\author{
BY \\ GEORGE M. MAXWELL, GEORGE G. ROWE and CHARLES W. CRUMPTON \\ From the Department of Pediatrics and the Cardiovascular Laboratory, University of Wisconsin, Madison 6 , \\ Wisconsin, U.S.A.
}

(RECEIVED FOR PUBLICATION JULY 5, 1957)

The concept of ventricular septal defect as a disease of little severity (Roger, 1879; Brown, 1950), has been upset by the observations of Marquis (1950) and Engle (1954). The median age at death in Abbott's (1951) cases was $14 \frac{1}{2}$ years; however, in common with others, we have observed severe disability and death in many younger children.

The advent of surgical therapy for this defect (Lillehei, Cohen, Warden, Ziegler and Varco, 1955), and the desirability of correction at an early age make it worth while to review the clinical features in the earliest age group. The haemodynamic findings will be given in some detail.

\section{Material and Methods}

Sixteen cases of ventricular septal defect occurring in infants aged 1 year or less were studied in 1955 . Table 1 shows the age at onset of symptoms and examination. Special studies were undertaken because of significant disease, and a large percentage thus observed was less than 6 months of age. Cardiac catheterization was done in the usual fashion using the Waters-Conley cuvette oximeter for oxygen saturation assessment. Its accuracy was checked by two or more Van Slyke specimens. Expired air was collected in a Tissot spirometer and analysed for oxygen and carbon dioxide content by the Scholander method. Calculations of shunts and resistances were by the usual formulae.

The catheter was normally placed in the femoral vein after the infant had received light basal (barbiturate) anaesthesia. Procaine $(1 \%)$ was used as a local supplement. Two patients who had suffered congestive failure received oxygen throughout the catheterization, as it was felt that arrhythmias were less frequent in this circum- stance. Difficulty was found in recording adequate pulmonary capillary pressures. We have found this also in adults with a large left-to-right shunt where more advantageous circumstances exist. The femoral vein was routinely ligated. No death or complication attributable to catheterization occurred.

\section{Clinical Features}

The Symptoms. These (Table 2) are surprisingly constant, and compare well with those found in other severe left-to-right shunts. They consist principally in failure of growth, refusal to feed. frequent respiratory infections and a 'murmur',

TABLE 2

CLINICAL HISTORY IN 16 CASES

\begin{tabular}{|c|c|c|c|c|}
\hline & Number & Percentage \\
\hline $\begin{array}{l}\text { Presenting Complaints } \\
\text { Cough and respiratc } \\
\text { Failure of growth } \\
\text { Dyspnoea } \quad . . \\
\text { 'Murmur' .. } \\
\text { Easy fatiguability } \\
\text { Cyanosis } \quad . . \\
\text { Rapid heart .. }\end{array}$ & 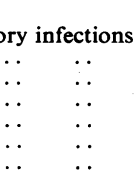 & \begin{tabular}{l|} 
\\
$\cdots$ \\
$\cdots$ \\
$\cdots$ \\
$\cdots$ \\
$\cdots$ \\
$\cdots$
\end{tabular} & $\begin{array}{r}10 \\
9 \\
3 \\
3 \\
2 \\
1 \\
1\end{array}$ & $\begin{array}{l}62 \\
56 \\
19 \\
19 \\
12 \cdot 5 \\
6 \\
6\end{array}$ \\
\hline \multicolumn{3}{|c|}{ 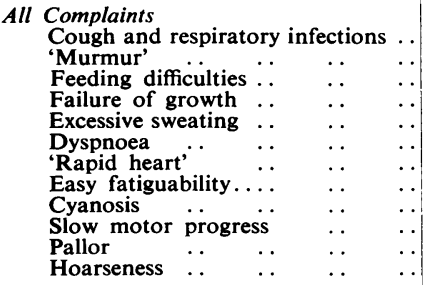 } & $\begin{array}{r}13 \\
13 \\
9 \\
9 \\
7 \\
5 \\
2 \\
2 \\
2 \\
1 \\
1 \\
1\end{array}$ & $\begin{array}{l}81 \\
81 \\
56 \\
56 \\
44 \\
31 \\
12 \cdot 5 \\
12 \cdot 5 \\
12 \cdot 5 \\
6 \\
6 \\
6\end{array}$ \\
\hline
\end{tabular}

TABLE 1

DISTRIBUTION OF PATIENTS ACCORDING TO ONSET OF SYMPTOMS AND AGE AT CATHETERIZATION

\begin{tabular}{|ll|c|c|c|c|c|c|c|c|c|}
\hline & & Birth to 1 Month & $2-3$ Months & 4-5 Months & $5-7$ Months & $8-9$ Months & $10-12$ Months \\
\hline Age at onset of symptoms & $\ldots$ &. & & 4 & 5 & 4 & - & - \\
\hline Age seen and catheterized & $\ldots$ & $\ldots$ & $2^{*}$ & 1 & 2 & 2 & 4 & 4 \\
\hline
\end{tabular}

* Not catheterized until 2 months of age. 
This latter was only rarely noted by the parents themselves. The early onset (Table 1) is noteworthy in some of the cases. Cyanosis-a rare feature in most adult series-occurred in some children. Excessive sweating in the absence of overt infections was not unusual. This has, however, been observed by us in other types of congenital heart disease. Lassitude-so commonly noted by the paediatrician -was seldom remarked upon by the parents. In a few cases the thrill was obvious to the family. Epistaxes, though common in older children with this defect, were absent in the patients studied.

The Signs. The most remarkable sign (Table 3) is growth failure; it occurs in most infants whose

TABLE 3

PRINCIPAL SIGNS

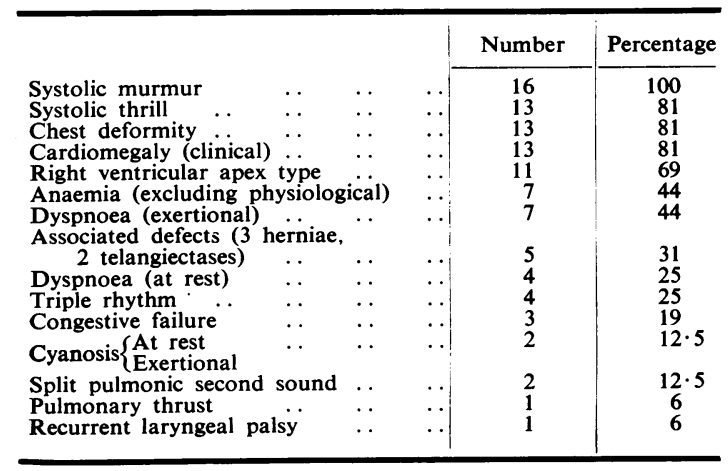

parents seek medical advice. Table 4 expresses this phenomenon in terms of growth percentile. It is seen that weight deficit is greater than height deficit though this latter is considerable. Head and chest size also tend to fall in the lower percentiles.

Further inspection often reveals Harrison's grooves (Fig. 1); these seem to be associated with dyspnoea or frequent respiratory infections. Breathlessness at rest is variable; this symptom occurs more often on exercise-usually crying and defaecation. Two cases showed cyanosis. Minor associated defects were found in five infants. The severe nature of the lesion is illustrated by the onset of congestive cardiac failure in three children. In two this responded adequately to therapy. Cough was by far the commonest sign in some of the infants; usually unassociated with cardiac failure, it may be subsequent to a change in the pulmonary blood flow.

Cardiovascular examination gave a constant picture. Enlargement of the heart was usual, as this was one of the criteria for further study. The apical impulse was frequently of the right ventricular type.
A gallop rhythm was occasionally palpated inside the displaced apex. A systolic thrill was felt over the lower left interspaces. It was coarse and widespread, corresponding well to Roger's original description. The thrill, however, may not appear for several months after birth. We have had the opportunity to observe two patients from birth, in whom no thrill could be felt until 3 and 4 months of age respectively. Similar findings have been observed in some cases of Fallot's tetralogy (Maxwell, 1954).

The character of the second sound at the pulmonary area is of some interest. It has been observed by Leatham (1952) that a widely split second sound is common in left-to-right shunts, usually in association with electrocardiographic evidence of right bundle branch block. Wood (1950) noted this sign in older patients with ventricular septal defect. This elegant clue was seldom found in the infant group studied here. Generally auscultation reveals a single sound, as in normal infants. Again, pathological intensity of this sound has not been observed, an expected finding in view of the wide range in normals of this age.

Apical diastolic murmurs were not heard in this group, which contrasts with Wood's (1950) findings for older patients with the same defect.

Anaemia is not uncommon. An attempt was made to exclude the 'physiological' anaemia of infancy in assessing the figures, and there is some

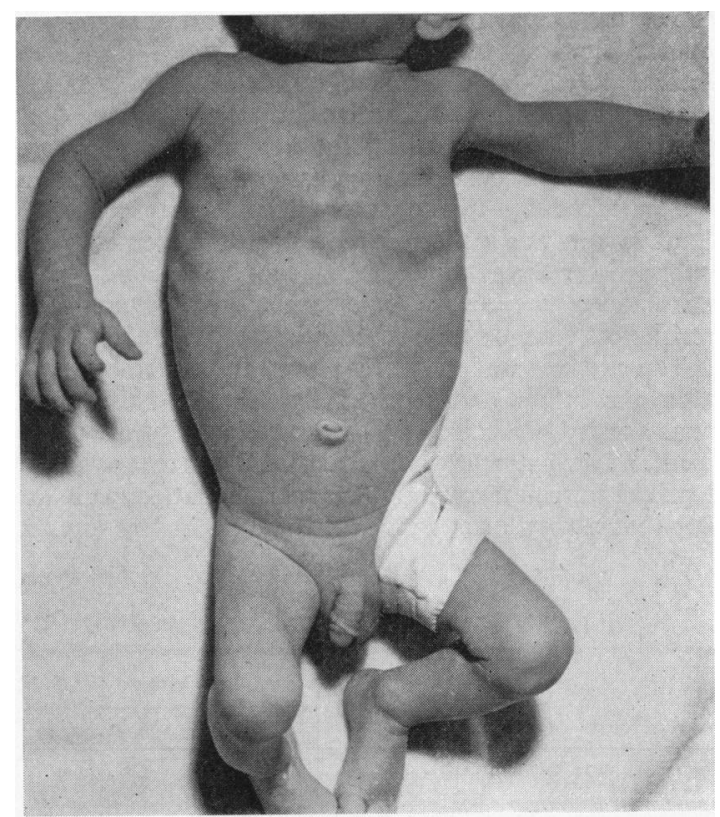

Fig. 1.-Note the Harrison's grooves. 
evidence that a true iron-deficiency state exists. Certainly difficulty is found in introducing a mixed, iron-containing diet to these infants, and a staple diet of cow's milk is usually deficient in this element. The frequent infections introduce another need for iron (Wintrobe, 1951) and aggravate the condition.

These infants are lethargic and inactive. Muscular hypotonia is not unusual and this combination results in failure to pass the milestones of motor development at the proper time. Thus the ages of rolling over, sitting up and crawling may be delayed. Observation of other older cases suggests that those who live may catch up in the second and third years.

The single case of laryngeal palsy is not very unusual, though it is perhaps more common in cases of atrial septal defect.

\section{Discussion of Clinical Features}

The history is that of any severe left-to-right shunt, resembling most closely that of a 'malignant' patent ductus. Like the latter, the symptoms may exist from the perinatal period and are characterized by feeding problems, failure of growth, respiratory infections and a murmur. This latter corresponds with the description given for older children and adults. The thrill, however, may not appear until some months have elapsed. The murmur and thrill may be confused with that of aortic or subaortic stenosis; we have encountered four such cases in the period of this study. In these the murmur and thrill were not distinguishable from those of ventricular septal defect. However, good growth and lack of cardiomegaly and pulmonary plethora were useful differential points. They are more difficult to tell from cases of ventricular septal defects without pulmonary hypertension. A similar difficulty was reported by Taussig (1955). Brachial arterial tracing may be a useful distinguishing point.

\section{Radiology}

As a result of selection, enlargement of the heart was usual. Biventricular increase was common, and differentiation of the major chamber enlargement was difficult in these circumstances. The pulmonary arc was prominent, and the lung fields engorged: relative peripheral hypovascularity was seen in several patients, reflecting perhaps the situation reported by Hultgren, Selzer, Purdy, Holman and Gerbode (1953), in cases of patent ductus with pulmonary hypertension. The linear markings of Kerley (1951) were not seen. This was not unexpected, as this sign is related to the level of the pulmonary capillary pressure and not to the pulmonary arterial tension (Bruwer, Ellis, and Kirklin, 1955).
A corollary to increased pulmonary blood-flow is increased left atrial size. This has been said (Keats and Steinbach, 1955) to be characteristic of patent ductus. However, the left atrium may be prominent in any condition with pulmonary plethora and intact atrial septum. Brostoff and Rodbard (1956) have demonstrated the hydrodynamic cause in simulated ventricular septal defect.

Common radiological findings are illustrated in Figs. 2, 3, 4 and 5.

It will be seen that the findings in severe ventricular septal defect are very similar to those reported in 'malignant' patent ductus by Adams, LaBree and Stauffer (1950); it is probable that many cases are radiologically indistinguishable by ordinary techniques. While hypervascularity and right ventricular enlargement will occur in some cases of atrial septal defect, we have not noted left atrial enlargement in this condition. This is perhaps a useful differential point.

Routine angiocardiography has been of little value in delineating this lesion, and has only occasionally been employed by us. The size of the right ventricle and pulmonary arteries may sometimes be shown by this method, and the left ventricular dimension assessed by difference.

\section{Electrocardiography}

Most cases showed a right bundle branch block, often of the complicated type associated with increase in the right ventricular work (Wasserburger, 1956). Some cases may also show evidence of delay in activation time over the left ventricle in addition to the previous finding.

However, the electrocardiogram of ventricular septal defect is by no means unique; similar patterns may be found in patent ductus, again with signs of right and left ventricular overloading. The haemodynamic coincidence of these two lesions render this a reasonable finding. A common E.C.G. pattern is seen in Fig. 6.

\section{Cardiac Catheterization}

A. Diagnosis. The primary reason for the studies was confirmation and quantitation of the clinical diagnosis, and this was readily done in most cases. The increase in oxygen content from atrium to ventricle averaged $2.5 \mathrm{vol}$. in those studied while breathing room air. One case (No. 3 in Table 4) required $100 \%$ oxygen before the level of shunt was apparent. This was because of the extraordinayr degree of unsaturation present. Table 5 illustrates this point comparatively. In no case did we require to give adrenalin to show the level of shunt as has been suggested by Condorelli (Turchetti, 1954). 


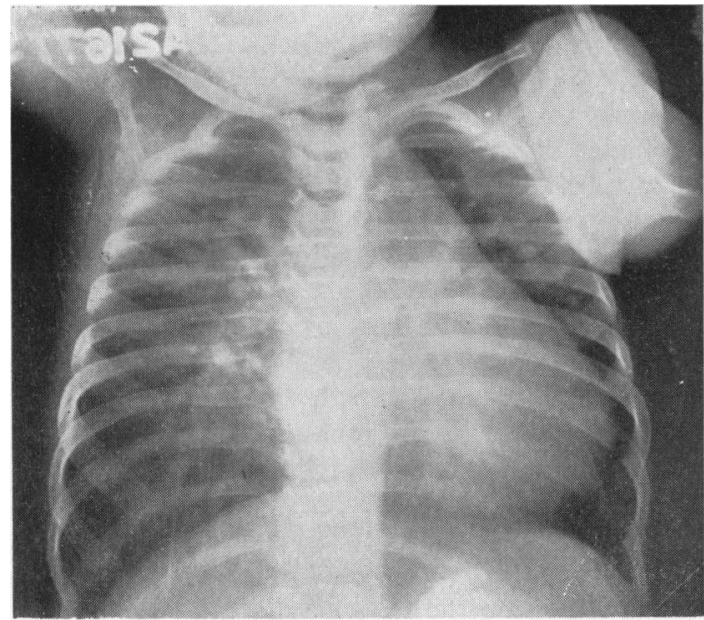

FIG. 2.-In this postero-anterior view there is cardiac enlargement, pulmonary plethora and prominence of the pulmonary arc.

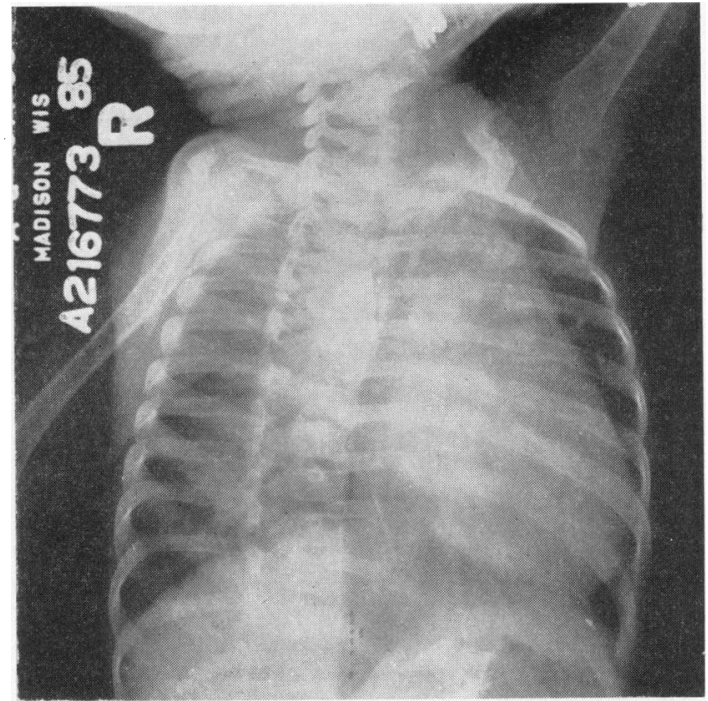

Fig. 3.-This R.A.O. view shows the right ventricular enlargement.

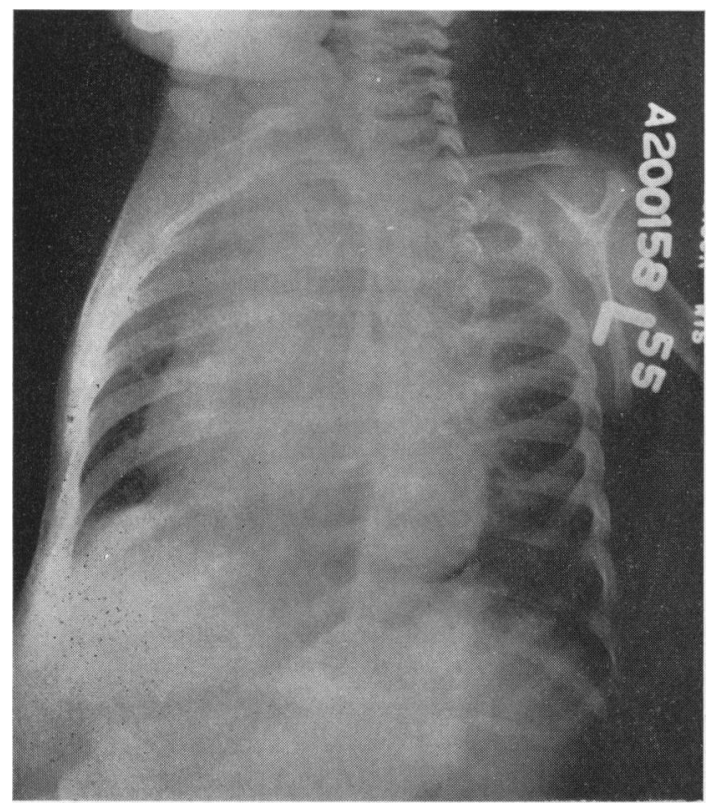

FIG. 4.-Note the enlarged left ventricle in this L.A.O. view.

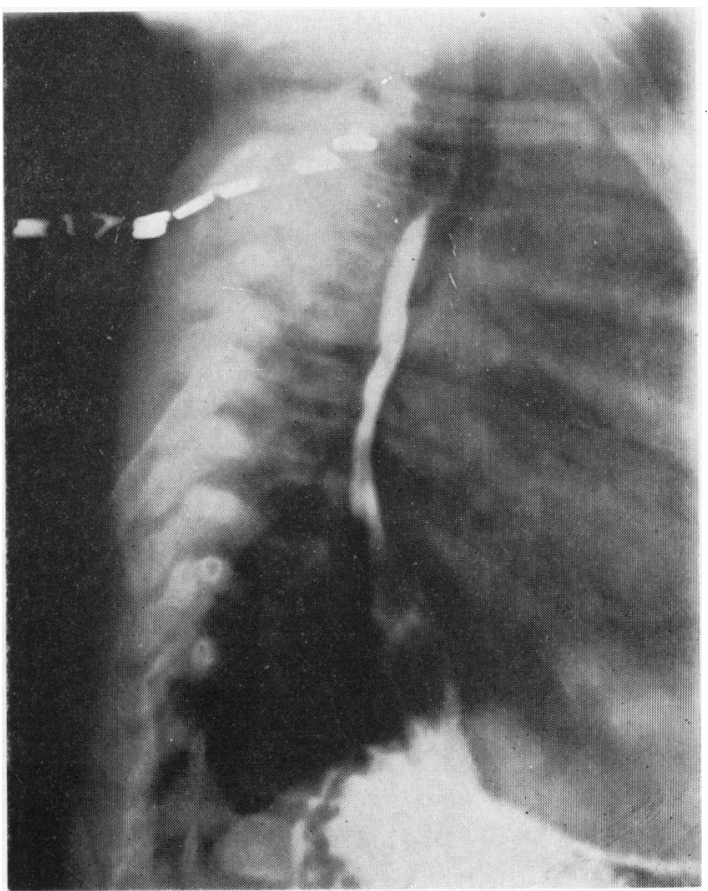

Fig. 5.-The left atrium has displaced the oesophagus in this right oblique view. 

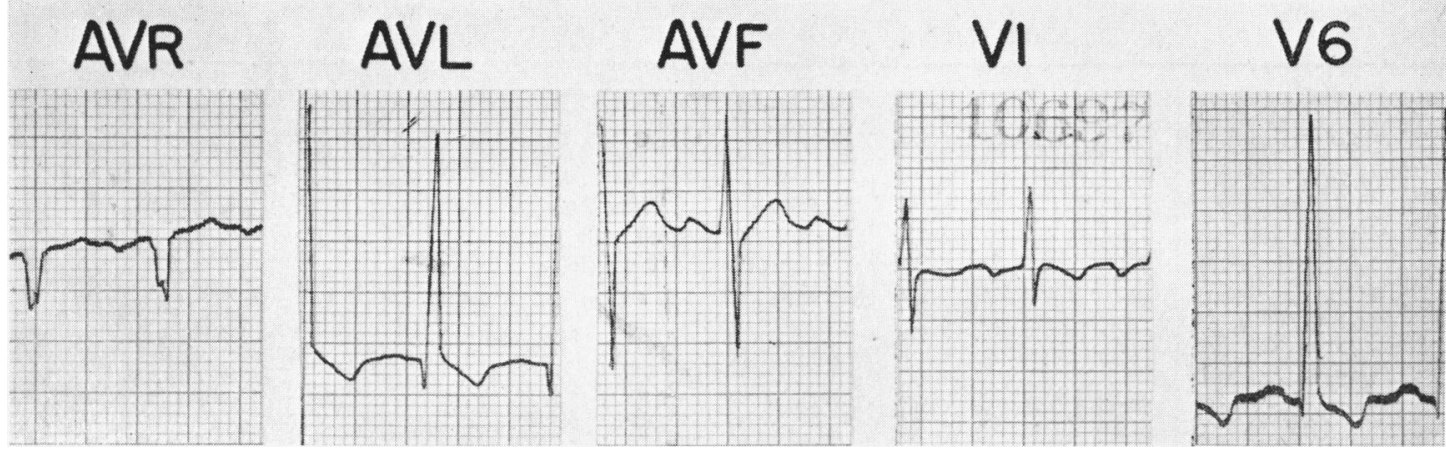

Fig. 6.-The E.C.G. of a case of ventricular septal defect aged 7 months. There is a delay in ventricular activation time over the left ventricle, i.e., V.A.T. $=0 \cdot 035-0.040 \mathrm{sec}$.

In some cases the left atrium was entered by way of a foramen ovale; that this was not a functioning defect was suggested by the lack of arterialization of the right atrium, and full saturation of the left atrium as compared with the pulmonary veins. The left ventricle was occasionally explored by this route also. In this age group, the technical problem of moving the catheter within the pulmonary circuit makes the exclusion of a patent ductus difficult*

* In one case since operated upon, a functioning patent ductus was found.
TABLE 5

SATURATION LEVELS IN CASE 3 BREATHING AIR AND OXYGEN

\begin{tabular}{|c|c|c|c|c|}
\hline \multirow[t]{2}{*}{ Site } & & & \multicolumn{2}{|c|}{$\mathrm{O}_{2}$ Saturation $\%$} \\
\hline & & & Air & $100 \%$ Oxygen \\
\hline $\begin{array}{l}\text { Superior vena cava } \\
\text { Mid right atrium } \\
\text { Low right ventricle } \\
\text { Main pulmonary artery } \\
\text { Left pulmonary artery } \\
\text { Femoral artery } \quad \text {. }\end{array}$ & $\begin{array}{l}\cdots \\
\cdots \\
\cdots \\
\cdots \\
\cdots\end{array}$ & \begin{tabular}{l|}
$\cdots$ \\
$\cdots$ \\
$\cdots$ \\
$\cdots$ \\
$\cdots$
\end{tabular} & $\begin{array}{l}22 \\
23 \\
23 \\
23 \\
24 \\
52\end{array}$ & $\begin{array}{l}72 \\
77 \\
90 \\
97 \\
96 \\
97\end{array}$ \\
\hline
\end{tabular}

TABLE 4

VENTRICULAR SEPTAL DEFECT

Nutrition in 16 Cases

\section{PERCENTILE}

HEIGHT $93 \%$ in 25 th or lower percentile

\section{WEIGHT}

90 $93 \%$ in 10 th or lower percentile

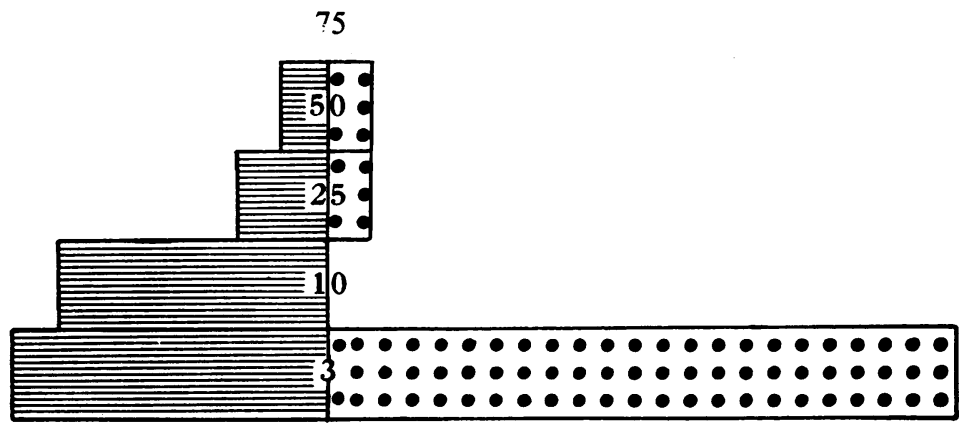

12

\begin{abstract}
8
\end{abstract}
Number
4

The percentile table shows that the majority of patients were severely malnourished. 
TABLE 6

HAEMODYNAMICS OF VENTRICULAR SEPTAL DEFECT

\begin{tabular}{|c|c|c|c|c|c|c|c|c|c|c|c|c|c|c|c|c|c|c|}
\hline $\begin{array}{l}\dot{0} \\
\mathbf{Z} \\
\dot{y} \\
\tilde{U}\end{array}$ & $\underset{4}{\infty}$ & 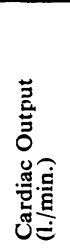 & 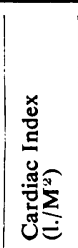 & 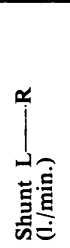 & 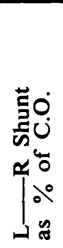 & 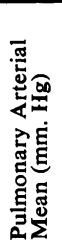 & 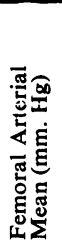 & 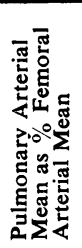 & 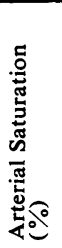 & 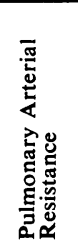 & 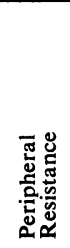 & 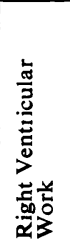 & 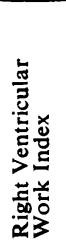 & 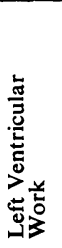 & 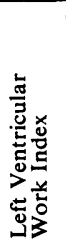 & 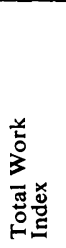 & 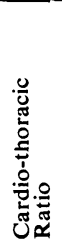 & $\begin{array}{l}\hat{d} \\
\frac{5}{30} \\
\frac{50}{3}\end{array}$ \\
\hline $\begin{array}{r}1 \\
2 \\
3 \\
4 \\
5 \\
6 \\
7 \\
8 \\
9 \\
10 \\
11 \\
12 \\
13 \\
14 \\
15 \\
16\end{array}$ & $\begin{array}{r}2 / 12 \\
7 / 12 \\
3 / 12 \\
4 / 12 \\
9 / 12 \\
3 / 12 \\
2 / 12 \\
6 / 12 \\
8 / 12 \\
9 / 12 \\
8 / 12 \\
4 / 12 \\
11 / 12 \\
12 / 12 \\
12 / 12 \\
12 / 12\end{array}$ & $\begin{array}{c}1.0 \\
2.4 \\
\text { See T } \\
1 \cdot 5 \\
1.1 \\
1.0 \\
1 \cdot 1 \\
1.7 \\
1.6 \\
1.4 \\
2.6 \\
1.5 \\
2.8 \\
4.0 \\
1.7 \\
3.7\end{array}$ & $\begin{array}{r}4 \cdot 3 \\
8 \cdot 1 \\
\text { able } 5 \\
5 \cdot 4 \\
3 \cdot 2 \\
4 \cdot 1 \\
3 \cdot 7 \\
5 \cdot 6 \\
5 \cdot 0 \\
4 \cdot 4 \\
8 \cdot 6 \\
6 \cdot 3 \\
7 \cdot 5 \\
7 \cdot 7 \\
3 \cdot 8 \\
7 \cdot 8\end{array}$ & $\begin{array}{l}0 \cdot 76 \\
0 \cdot 83 \\
4 \cdot 5 \\
2 \cdot 0 \\
0 \cdot 5 \\
0 \cdot 9 \\
3 \cdot 6 \\
6 \cdot 3 \\
4 \cdot 2 \\
3 \cdot 0 \\
1.9 \\
1 \cdot 3 \\
1 \cdot 7 \\
4 \cdot 4 \\
3 \cdot 1\end{array}$ & $\begin{array}{r}76 \\
34 \\
\\
300 \\
182 \\
50 \\
82 \\
211 \\
343 \\
300 \\
115 \\
126 \\
46 \\
42 \\
258 \\
84\end{array}$ & $\begin{array}{l}58 \\
77 \\
\\
42 \\
67 \\
50 \\
26 \\
54 \\
33 \\
57 \\
30 \\
50 \\
56 \\
55 \\
26 \\
18\end{array}$ & $\begin{array}{l}53 \\
71 \\
\\
70 \\
77 \\
71 \\
73 \\
79 \\
69 \\
66 \\
65 \\
73 \\
68 \\
59 \\
60 \\
74\end{array}$ & $\begin{array}{r}109 \\
108 \\
\\
60 \\
87 \\
70 \\
35 \\
68 \\
47 \\
86 \\
46 \\
68 \\
82 \\
93 \\
41 \\
24\end{array}$ & $\begin{array}{l}58 \\
85 \\
92 \\
99 \\
93 \\
93 \\
93 \\
87 \\
95 \\
90 \\
95 \\
85 \\
92 \\
90 \\
96\end{array}$ & $\begin{array}{r}2,636 \\
2,522 \\
\\
618 \\
2,279 \\
2,724 \\
1,057 \\
737 \\
340 \\
795 \\
466 \\
1,163 \\
1,338 \\
715 \\
346 \\
209\end{array}$ & $\begin{array}{l}4,227 \\
2,326 \\
3,813 \\
5,432 \\
5,802 \\
5,313 \\
3,751 \\
3,457 \\
3,684 \\
1,950 \\
4,051 \\
1,905 \\
1,192 \\
5,511 \\
1,610\end{array}$ & $\begin{array}{l}0 \cdot 8 \\
2 \cdot 5 \\
0 \cdot 8 \\
0 \cdot 7 \\
0 \cdot 6 \\
0 \cdot 4 \\
1 \cdot 1 \\
0 \cdot 7 \\
1 \cdot 1 \\
1 \cdot 4 \\
1 \cdot 0 \\
2 \cdot 0 \\
2 \cdot 6 \\
0 \cdot 5 \\
0 \cdot 4\end{array}$ & $\begin{array}{l}3 \cdot 5 \\
8 \cdot 3 \\
3 \cdot 0 \\
2 \cdot 0 \\
2 \cdot 8 \\
1 \cdot 3 \\
3 \cdot 7 \\
3 \cdot 3 \\
3 \cdot 4 \\
4 \cdot 4 \\
4 \cdot 3 \\
3 \cdot 2 \\
5 \cdot 0 \\
1 \cdot 0 \\
2 \cdot 0\end{array}$ & $\begin{array}{l}1 \cdot 3 \\
2 \cdot 4 \\
4 \cdot 0 \\
2 \cdot 5 \\
1 \cdot 2 \\
1 \cdot 1 \\
4 \cdot 2 \\
7 \cdot 4 \\
4 \cdot 6 \\
3 \cdot 1 \\
3 \cdot 3 \\
3 \cdot 1 \\
3 \cdot 9 \\
5 \cdot 0 \\
6 \cdot 9\end{array}$ & $\begin{array}{r}5 \cdot 7 \\
8 \cdot 0 \\
14 \cdot 3 \\
7 \cdot 0 \\
5 \cdot 2 \\
3 \cdot 7 \\
14 \cdot 2 \\
23 \cdot 0 \\
14 \cdot 4 \\
10 \cdot 0 \\
14 \cdot 4 \\
5 \cdot 0 \\
7 \cdot 9 \\
11 \cdot 0 \\
14 \cdot 6\end{array}$ & $\begin{array}{r}9 \cdot 2 \\
16 \cdot 3 \\
17 \cdot 3 \\
9 \cdot 0 \\
8 \cdot 0 \\
5 \cdot 1 \\
17 \cdot 9 \\
26 \cdot 3 \\
17 \cdot 8 \\
14 \cdot 4 \\
18 \cdot 7 \\
8 \cdot 2 \\
12 \cdot 9 \\
12 \cdot 0 \\
16 \cdot 6\end{array}$ & $\begin{array}{l}61 \\
66 \\
\\
59 \\
63 \\
62 \\
56 \\
69 \\
58 \\
58 \\
60 \\
60 \\
61 \\
62 \\
53 \\
46\end{array}$ & \begin{tabular}{|r}
-3 \\
-3 \\
-3 \\
3 \\
3 \\
3 \\
-3 \\
-3 \\
-3 \\
-3 \\
-3 \\
-3 \\
-3 \\
-3 \\
-3 \\
25 \\
-3 \\
50
\end{tabular} \\
\hline
\end{tabular}

since no faith can be put in the failure to traverse the ductus. An associated defect of this type therefore cannot be readily excluded in this age group by catheterization alone.

B. The Haemodynamics. These are summarized in Table 6.

1. The Pressures. Except in infants with congestive failure at the time of study, the levels in the great veins and right atrium were normal by comparison with adult standards.

Right ventricular hypertension was found in all but one case (16) of the series; this was carried forward into the pulmonary circuit essentially unchanged. No case was found to have the 'relative' pulmonary stenosis occasionally found in older persons with large left-to-right shunts. Its absence is probably related to the severe clinical condition and elevated total pulmonary resistance found in these infants.

Normal pressure levels for this age group have not been published, but sporadic observations in this unit in infants with compensated aortic stenosis suggest that adult standards hold good at least as early as 6 months of age. Case 16 would be normal by these criteria. Comparison of the pulmonary arterial mean pressures with the mean in the femoral artery showed that the former was $68 \%$ or more of the latter in 10 of the 16 cases. The implication of this is that these 10 children would be considered as poor surgical risks by the criteria of Lillehei $e t$ al. (1955). This pressure relationship if abnormal does not appear to be associated with the clinically assessed severity of these cases, e.g., by nutrition, presence of dyspnoea or cardio-thoracic ratio. A normal relationship, as seen in Case 16, was in a child who had the highest growth percentile and a normal $(46 \%)$ cardio-thoracic ratio. As expected, there is a suggestive relationship between a high mean pulmonary femoral pressure and the presence of arterial desaturation. However, as in Case 14, full saturation may be present even if the pulmonary arterial pressure mean is $93 \%$ of that in the femoral vessel.

Perusal of the peripheral saturation values, however, does show that significant oxygen unsaturation was present in seven of the 16 cases. This is again a contraindication to surgery in the views of Lillehei and his colleagues.

The pulmonary wedge pressures, where obtainable, were commonly within normal limits for the adult range.

2. Cardiac Output and Shunts. In the absence of control values for this age group, these figures are presented without comment. The high cardiac index in several of these children has been observed by us in older infants and children found to have no abnormality at cardiac catheterization. An index may be an unreliable concept in these small patients whose surface area is disproportionately greater per unit volume than in the adult. Additionally, the effect of the anaesthetic must be considered in the assessment of these results. The volume of shunt was three times or more the cardiac output in five of the patients and less than the cardiac output in six. As compared with older children studied in our laboratory, the left-to-right shunt is less in this group 
which had a higher incidence of right ventricular hypertension. Conversely, right-to-left shunts were more common, and caused the high incidence of arterial unsaturation which has already been commented upon.

The resistances echo the phenomena already described; a high total pulmonary resistance was usual. This is in contradistinction to the normal or lower resistances found in many older children with a more benign lesion. Our only exception was Case 16, a patient who is perhaps more typical in this respect. The pulmonary arteriolar resistance (where calculable) contributes somewhat to this increase. The total peripheral resistances are in many cases high by adult standards, but this again may not be pathological for this group as it has been sporadically observed in normals of the same age studied in this department.

3. CARDIAC WORK. The right ventricular work was calculated on the assumption that the shunt occurs in systole and that this chamber does not contract upon the shunted blood. The results show that the amount of work done by the right ventricle is greatly increased by adult standards when expressed as a work index (R.V. work). This is,

$$
\text { (Surface area) }
$$

of course, a function of the raised pulmonary pressure. The left ventricular work is similarly increased by index values because of the left-to-right shunt.

Summation of the left and right ventricular work indices gives an estimate of the total work done by the heart in this condition. It is very likely, however, that values for normals in this age group are higher than for adults in this respect, because of the high peripheral resistance already mentioned, and the exaggerating tendency of a low surface area.

\section{Discussion}

This group illustrates the severe clinical and haemodynamic change in a series of infants with ventricular septal defect. It is seen that the problem in this age group is not of the shunt, but of the resultant or coincident pulmonary hypertension. This may occur very early in life. It was proven to exist as early as 2 months of age in Case 1 . Clinically in this and in Case 3, the condition may have been present in the first two weeks of life. The resultant rise in ventricular and total work indices is very marked in the majority, and explains the high incidence of right-sided failure in this and other series (Engle, 1954). Growth failure is severe, but cannot be statistically related to the pulmonary arterial pressure if this is abnormal; nor in the absence of normal values to the cardiac output. If pulmonary pressure and arterial desaturation is considered in relation to operability, over half of these infants might not be aided by surgery. This trend might be reversed if these children are studied very early in life, though again cases occurred as early as 2 months in which surgery could not be advised. During the period of follow-up one child (Case 14) died of congestive cardiac failure; three others died suddenly at the beginning of a respiratory infection before surgery could be carried out.

\section{Summary}

The clinical and radiological features of a series of infants with ventricular septal defects are presented. The resultant effects on the haemodynamics are noted and discussed.

This study was supported in part by the Wisconsin Alumni Research Foundation and the Wisconsin Heart Association.

\section{REFERENCES}

Abbot, M. E. (1951). In Disorders of the Heart and Circulation, ed. R. L. Levy. New York.

Adams, F. H., LaBree, J. and Stauffer, H. M. (1950). Pediatrics, 5, 390 .

Brostoff, P. and Rodbard, S. (1956). Amer. Heart J., 51, 325.

Brown, J. W. (1950). Congenital Heart Disease, 2nd ed. London. Bruwer, A. J., Ellis, F. H., Jr. and Kirklin, J. W. (1955). Circulation, 12, 807 .

Engle, M. A. (1954). Pediatrics, 14, 16

Hultgren, H., Selzer, A.. Purdy, A., Holman, E. and Gerbode, F. (1953). Circulation, 8, 15.

Keats, T. E. and Steinbach, H. L. (1955). Radiology, 64, 528.

Kerley, P. (1951). In A Textbook of X-ray Diagnosis, 2 nd ed., ed. Shanks, S. C. and Kerley, P. Vol. 2. London.

Leatham, A. (1952). Brit. med. Bull., 8, 333.

Lillehei, C. W., Cohen, M., Warden, H. E., Ziegler, N. R. and Varco, R. L. (1955). Surg. Gynec. Obstet., 101, 446 .

Marquis, R. M. (1950). Brit. Heart J., 12, 265.

Maxwell, G. M. (1954). Congenital Heart Disease in the Paediatric, Age and Group. M.D. Thesis. University of Edinburgh.

Roger, H. (1879). Bull. Acad. Méd. (Paris), ser. 2, 8, 1074, 1189.

Taussig, H. B. (1955). Proc. Ann. Meet. Amer. Heart. Ass. New Orleans.

Turchetti, A. (1954). Proc. 2nd World Cong. of Cardiology, Washington, 1954. Abstract in Acta cardiol (Brux.), 9, 592.

Wasserburger, R. W. (1956). Proc. Ann. Meet. Wisc. Heart Ass. To be published.

Wintrobe, M. M. (1951). Clinical Hematology, 3rd ed., p. 540 Philadelphia.

Wood, P. (1950). Brit. med. J., 2, 639. 